\title{
Studi Perbandingan tentang Sifat Mekanik dan Struktur Mikro Material Radiator Impor dan Material Radiator Lokal
}

\author{
Rahmada, Usman Sudjadi ${ }^{b}$ \\ a Universitas Mercu Buana, meruya selatan, Jakarta, Indonesia, \\ e-mail: rahmadjayadiningrat@gmail.com \\ b,c Universitas Mercu Buana, meruya selatan, Jakarta, Indonesia \\ e-mail: umardjasipan@gmail.com
}

Kata kunci:

pemanasan,

komposisi

kimia,

struktur

mikro

kekerasan,

korosi.

Keyword:

heating, chemical

composition, hardness

microstructure,

corrosion

\section{ABSTRAK}

Pengujian pada studi ini menggunakan sampel core radiator impor dan core radiator lokal. Metode pengujian dilakukan dengan tiga tahapan yaitu sebelum heat treatment, sesudah heat treatment, dan uji korosi dengan direndam cairan yang berbeda yaitu $\mathrm{H} 2 \mathrm{SO} 4, \mathrm{NAOH}$, dan cairan radiator selama 15 hari. Sebelum heat treatment, dilakukan uji komposisi kimia semua sampel radiator dengan alat XRF, uji struktur mikro dengan mikroskop optik pembesaran 500x, dan uji kekerasan micro-vickers dengan beban $100 \mathrm{gf}$ dalam waktu 10 detik. Heat treatment dilakukan dengan suhu $850^{\circ} \mathrm{C}$ dalam waktu 3 jam, kemudian direndam dengan cairan kimia selama 15 hari. Dari pengujian tersebut didapat hasil uji struktur mikro baik sebelum maupun sesudah heat treatment pada kedua sampel radiator tidak terlihat kumpulan atom, matrix dan batas butirnya. Uji kekerasan pada sampel core radiator Mercedez sebelum dipanaskan sebesar 43,4 HV dan 39,2 HV sesudah heat treatment. Pada core radiator lokal, sebelum dipanaskan sebesar 43,5 HV dan 38,2 HV sesudah dipanaskan. Hasil uji komposisi kimia menunjukan pada sampel core Mercedez didominasi unsur $\mathrm{Ca}, \mathrm{Mn}$, dan Fe dan pada sampel core radiator lokal didominasi unsur $\mathrm{Ca}, \mathrm{Cu}$ dan $\mathrm{Zn}$. Hasil pengamatan dan analisa setelah direndam cairan $\mathrm{H} 2 \mathrm{~S} 04, \mathrm{NAOH}$, dan cairan radiator pada kedua sampel menunjukkan terjadinya perubahan warna karena adanya perubahan unsur akibat peningkatan konsentrasi atom.

\section{ABSTRACT}

Sample in this study sampled core radiator of import and local core radiator. The test method was carried out in three stages, namely before heat treatment, after heat treatment, and corrosion testing by immersing for 15 days in different liquids, namely $\mathrm{H} 2 \mathrm{SO} 4, \mathrm{NAOH}$, and radiator fluid Before heat treatment, a chemical composition test was carried out with all samples using XRF, microstructure test with an optical microscope with 500x magnification and micro-vickers hardness test with $100 \mathrm{~g}$ fload within for 10 seconds. Heat treatment with a temperature of $850 \mathrm{oC}$ within for 3 hours, then after that soaked in chemical liquid for 15 days. The results showed that the microstructures of both before and after heat treatment on the two radiator samples did not show atoms, matrix, and grain boundaries. The hardness number of the import radiator core samples before being heated was $43.4 \mathrm{HV}$ and $39.2 \mathrm{HV}$ after heat treatment and those of local radiator core $43.5 \mathrm{HV}$ and $38.2 \mathrm{HV}$ respectively. The chemical composition test show that the Mercedez core samples are dominated by the $\mathrm{Ca}, \mathrm{Mn}$, and $\mathrm{Fe}$, and the local radiator core samples are dominated by the elements $\mathrm{Ca}, \mathrm{Cu}$, and $\mathrm{Zn}$. After being immersed in $\mathrm{H} 2 \mathrm{SO}, \mathrm{NAOH}$, and radiator fluids the color of both samples changed due to changes in elements composition caused by the increase in atomic concentration. 


\section{PENDAHULUAN}

Performa mobil dipengaruhi oleh beberapa hal, salah satunya kualitas pendingin mesin atau radiator. Radiator memiliki peran penting untuk menjaga suhu kendaraan karena peningkatan suhu kendaraan akan menyebabkan kerusakan mesin, tidak efisiennya bahan bakar, dan peningkatan polusi [1]. Radiator dibuat dengan berbagai macam bahan seperti besi, baja, paduan aluminium, dan perunggu. Kualitas radiator perlu dijaga agar tidak terjadi kegagalan seperti kebocoran radiator akibat panas suhu mesin [2]. Radiator digunakan untuk mendinginkan mesin dari proses pembakaran pada kendaraan bermotor yang prinsipnya didinginkan dengan mengalirkan fluida melalui blok mesin [3]. Berdasarkan data Kementerian Perdagangan untuk impor kategori suku cadang kendaraan dari tahun 2015 hingga 2019, terdapat tren peningkatan nilai impor sebesar 24\% [4]. Ini menunjukkan bahwa Indonesia sangat bergantung pada komponen suku cadang yang diimpor. Kondisi ini bisa berdampak pada penggunaan produk spare part lokal. Saat ini radiator yang digunakan pada kendaraan khususnya mobil di Indonesia didominasi oleh produk impor, sedangkan produk lokal sulit bersaing dengan produk impor lainnya. Radiator biasanya digunakan pada kendaraan roda empat meski saat ini sepeda motor yang berkapasitas mesin 150cc keatas sudah menggunakannya. Perbedaan manufaktur mempengaruhi kualitas radiator, karena setiap pabrikan memiliki standarnya sendiri. Radiator memiliki beberapa komponen seperti inti radiator, tanki atas, dan tangki bawah. Inti radiator memiliki peran penting sebagai pelepas panas atau pendingin [5]. Inti radiator terdiri dari pada susunan pipa yang disusun oleh plat tipis yang berfungsi untuk mengeluarkan panas. Inti radiator berfungsi untuk memecah volume air melalui pipa-pipa kecil agar lebih mudah mendinginkan jika terkena angin dari hembusan kipas pendingin. Inti radiator terdiri dari dua jenis, sebagian terbuat dari tembaga dan sebagian lagi terbuat dari aluminium [6]. Perbedaan sifat mekanik material yang digunakan pada radiator dipengaruhi oleh komposisi kimia, heat treatment, dan mikrostruktur yang terbentuk [7].

Telah banyak penelitian tentang pengujian material radiator $[8,9,10]$, yang menarik [8] melakukan penelitian pada material radiator, bahwa penambahan tembaga pada aluminum akan meningkatkan kekerasan material. Hal ini menunjukkan bahwa setiap radiator memiliki spesifikasinya masing-masing dan mempengaruhi kualitas radiator. [9] Melakukan penelitian terhadap bahan penyusun radiator dengan menggunakan paduan tembaga dan kuningan. Hasil penelitian menunjukkan bahwa perbedaan komposisi antar paduan penyusun $(\mathrm{Cu}, \mathrm{Sn}, \mathrm{Pb}, \mathrm{Zn}$, dan $\mathrm{Fe})$ mengakibatkan perbedaan sifat mekanik. Permasalahan yang dihadapi saat ini adalah belum adanya penelitian yang membandingkan core radiator impor dengan produk lokal, sehingga perlu dilakukan penelitian untuk mengkarakterisasi (uji kekerasan, uji mikrostruktur, dan uji komposisi kimia) radiator mobil impor Mercedez Benz dan radiator produk lokal dengan membandingkan kualitas produk lokal dengan produk impor berdasarkan komposisi kimianya. Penelitian dilakukan untuk kepentingan pembelajaran bukan untuk bisnis.

\section{METODE PENELITIAN}

Material yang digunakan dalam studi karakterisasi ini adalah material inti radiator mobil Mercedez benz (Impor) dan material inti radiator mobil lokal (buatan Indonesia). Keduanya digunakan selama kurang lebih 5 tahun. Langkah pertama sebelum pengujian adalah memotong kecil-kecil dari masingmasing radiator, menggunakan metode manual yaitu menggunakan gergaji besi untuk memotong dan mengampelas untuk menghaluskan permukaannya, dan penggaris untuk mengukur diameternya. Teknik manual ini dilakukan untuk mendapatkan hasil yang maksimal sehingga sesuai dengan hasil pemotongan yang dapat digunakan untuk pengujian. Diameter bahan yang akan dipotong berukuran (Panjang $=1 \mathrm{~cm}$, Lebar $=1 \mathrm{~cm}$, Tebal $=1 \mathrm{~cm})$.

Material inti dapat dilihat pada gambar 2(a) dan material inti radiator lokal dapat dilihat pada gambar 2(b). Distribusi material ini dilakukan untuk memudahkan proses pengujian. Kedua material tersebut kemudian diuji dengan menggunakan uji kekerasan untuk mengetahui kemampuan suatu logam dalam menahan lekukan permanen [11]. Perlakuan panas juga dilakukan pada material inti radiator Mercedez dan inti radiator lokal. 


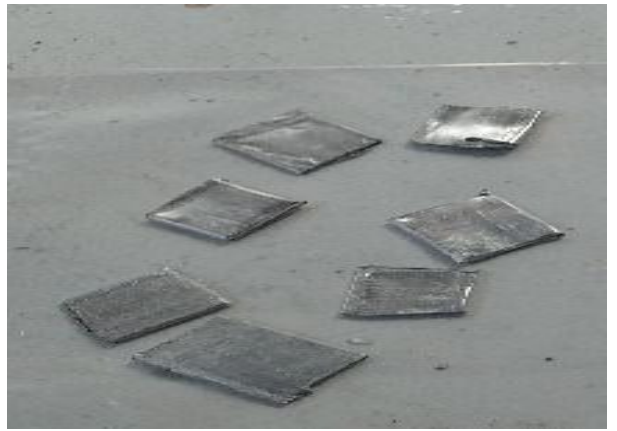

(a)

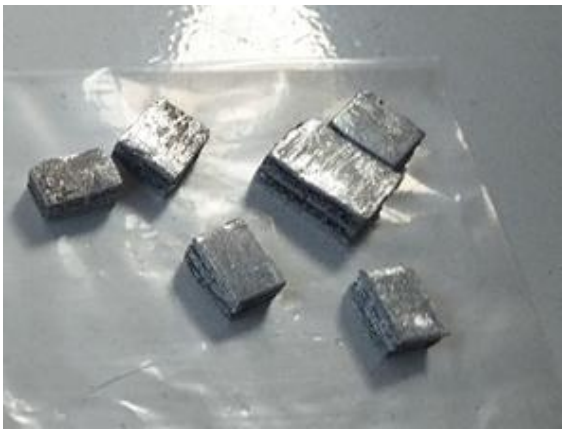

(b)

Gambar 1 (a) Sampel core Radiator impor (b) sampel core radiator lokal

Teknik pengujian dilakukan dalam tiga tahap, yaitu:

- Pengujian sebelum perlakuan panas

1. Pengujian struktur mikro menggunakan mikroskop optik dengan perbesaran 500x.

2. Uji komposisi kimia menggunakan XRF (X-ray Fluorence). Pengujian ini dilakukan untuk menentukan kandungan unsur kimia dan persentase yang terkandung dalam bahan inti radiator impor dan radiator lokal.

3. Pengujian kekerasan dengan micro-vickers yang bertujuan untuk mengetahui nilai rata-rata kekerasan setiap sampel, dengan beban $100 \mathrm{gr} / \mathrm{f}$ dalam waktu 10 detik.

- Pengujian setelah proses heat treatment

(sampel dipanaskan $850^{\circ} \mathrm{C}$, selama $\mathrm{t}=3$ jam) Setelah dilakukan heat treatment, maka sampel material radiator dilakukan pengujian kembali:

1. Uji kekerasan dengan micro-vickers menggunakan beban $100 \mathrm{gr} / \mathrm{f}$ dalam waktu 10 detik.

2. uji mikrostruktur dengan perbesaran 500x.

Perlakuan panas

Proses perlakuan panas dilakukan untuk mengetahui perubahan sifat-sifat logam. Perbedaan yang terjadi pada logam mempengaruhi perubahan seperti mikrostruktur selama proses perlakuan panas [12]. Pada studi karakterisasi ini, dilakukan heat treatment pada masing-masing sampel kedua jenis material radiator tersebut dengan temperatur $850^{\circ} \mathrm{C}$ dalam waktu 3 jam, dengan proses pendinginan temperatur ruangan normal. Pemanasan ini cukup tinggi (suhu perbedaan atom), bukan suhu temper $\left(100-500^{\circ} \mathrm{C}\right)$, karena sampel yang digunakan sudah digunakan kurang lebih 5 tahun, sehingga otomatis mengalami temper pemanasan sekitar $100^{\circ} \mathrm{C}$ saat digunakan di jalan raya. Dengan perlakuan panas suhu tinggi ini, dapat dilihat ada atau tidaknya perubahan struktur atom akibat self-diffuse dari atom-atom dalam material, dan secara otomatis akan mengubah sifat kekerasan dan mikro-struktur.

- uji korosi

Pengujian korosi pada kedua material inti radiator dilakukan dengan cara merendam menggunakan tiga cairan kimia yang berbeda, yaitu:

kedua material inti radiator direndam dengan cairan $\mathrm{H} 2 \mathrm{~S} 04, \mathrm{HAOH}$, dan cairan radiator yang umum dipakai untuk mengisi air radiator dalam waktu 15 hari. Setelah direndam dengan cairan kimia, selanjutnya kedua material tersebut dilakukan pengamatan dengan mikroskop optik untuk mengamati, kemudian dianalisa ada atau tidaknya perubahan struktur atom. Setelah proses uji korosi tersebut, dilakukan pengamatan komposisi unsur menggunakan XRF (X-ray Flourences) dan uji struktur mikro dengan mikroskop optik untuk mengamati kemudian menganalisa perubahan stuktur atom.

\section{HASIL DAN PEMBAHASAN}

\subsection{Hasil Uji Struktur Mikro Sebelum Pemanasan}

Gambar 2(a) memperlihatkan hasil uji struktur mikro pada material inti radiator impor sebelum proses perlakuan panas menggunakan mikroskop optik yang menunjukkan bahwa matriks atom dan batas butirnya belum terlihat, sehingga pembahasan ini hanya bersifat kualitatif. Pada gambar hanya terlihat sekelompok butiran putih dan sekelompok butiran hitam. Untuk mengetahui lebih jelas 
pengujian tersebut harus dilengkapi dengan pengujian SEM (Scanning Electron Microscope) dan EDX (Energy Dispersive X-Ray). Pada radiator lokal dapat dilihat pada Gambar 3b bahwa material radiator lokal belum terlihat kumpulan atom dan matriks serta batas butirnya, sehingga pembahasannya hanya bersifat kualitatif. Pada gambar tersebut hanya terlihat garis-garis memanjang hitam dan sekelompok besar butiran-butiran putih. Garis perpanjangan besar pada material radiator lokal lebih banyak dan lebih besar daripada material Radiator Mercedez.

\subsection{Hasil uji struktur mikro sesudah proses pemanasan}

Pada sampel material radiator impor, setelah dipanaskan pada temperatur $\mathrm{T}=850{ }^{\circ} \mathrm{C}$ dalam waktu $(\mathrm{t})=3 \mathrm{jam}$, hasil terlihat melingkar mengelilingi warna yang sangat hitam, seperti cincin melingkar, ada sedikit warna putih (lihat Gambar 3c). Sementara itu, material radiator lokal setelah pemanasan terlihat seperti potongan roda besar dan warnanya tidak terlalu hitam (lihat Gambar 3d).

\subsection{Hasil pengamatan dan analisa setelah uji korosi}

Hasil pengamatan dan analisa setelah uji korosi pada material inti radiator impor dengan direndam oleh cairan $\mathrm{H} 2 \mathrm{SO} 4$ (lihat gambar 3e ), ada beberapa unsur yang hilang karena terkorosi, dan ada juga unsur yang meningkat. Perubahan warna pada hasil uji struktur mikro material inti impor dipengaruhi oleh peningkatan unsur $\mathrm{Ca}$ dan $\mathrm{Cu}$, juga adanya perubahan unsur akibat peningkatan konsentrasi atom setelah direndam cairan $\mathrm{H} 2 \mathrm{SO}$.mHasil pengamatan dan analisa setelah uji korosi pada material inti radiator impor dengan direndam oleh cairan $\mathrm{NAOH}$ (lihat pada gambar 3g), ada unsur yang meningkat dan ada juga yang hilang karena terkorosi. Unsur yang meningkat setelah direndam dengan cairan $\mathrm{NAOH}$ ialah $\mathrm{Al}, \mathrm{Mn}, \mathrm{Fe}, \mathrm{Cu}, \mathrm{Zn}$ dn $\mathrm{Zr}$, sehingga perubahan warna pada gambar $3 \mathrm{~g}$ dipengaruhi oleh 6 unsur yang mengalami peningkatan konsentrasi yang mengakibatkan terjadi perubahan atom.mHasil pengamatan setelah uji korosi pada material inti radiator impor dengan direndam oleh cairan radiator (lihat pada gambar 3i), unsur $\mathrm{Al}, \mathrm{K}, \mathrm{Mn}, \mathrm{Fe}, \mathrm{Ga}$, dan $\mathrm{P}$ mengalami peningkatan konsentrasi, sehingga warna dari sebelum direndam mengalami perubahan.nHasil pengamatan dan analisa setelah uji korosi pada material inti radiator lokal dengan direndam oleh cairan $\mathrm{H} 2 \mathrm{SO} 4$ dapat dilihat pada gambar 3f. Perubahan warna pada hasil uji struktur mikro disebabkan adanya peningkatan unsur $\mathrm{Al}, \mathrm{S}, \mathrm{Mn}$, dan $\mathrm{Cu}$. Selain itu, perubahan strip atom dipengaruhi unsur - unsur lain yang mengalami perubahan. Hasil pengamatan dan analisa setelah uji korosi pada material inti radiator lokal dengan direndam oleh cairan $\mathrm{NAOH}$ (lihat gambar $3 \mathrm{~h}$ ), unsur $\mathrm{Al}, \mathrm{Mn}, \mathrm{Cu}$, dan $\mathrm{Zn}$ mengalami peningkatan konsentrasi setelah direndam, sehingga perubahan warna mikro struktur dipengaruhi unsur yang dominan dan yang tidak dominan. Hasil pengamatan dan analisa setelah uji korosi pada material inti radiator lokal dengan direndam oleh cairan radiator (lihat gambar $3 \mathrm{j}$ ), unsur $\mathrm{Al}, \mathrm{K}, \mathrm{Mn}, \mathrm{Zn}, \mathrm{Zr}$, dan P mengalami peningkatan konsentrasi setelah direndam, sehingga perubahan warna mikro struktur dipengaruhi unsur yang dominan dan yang tidak dominan.

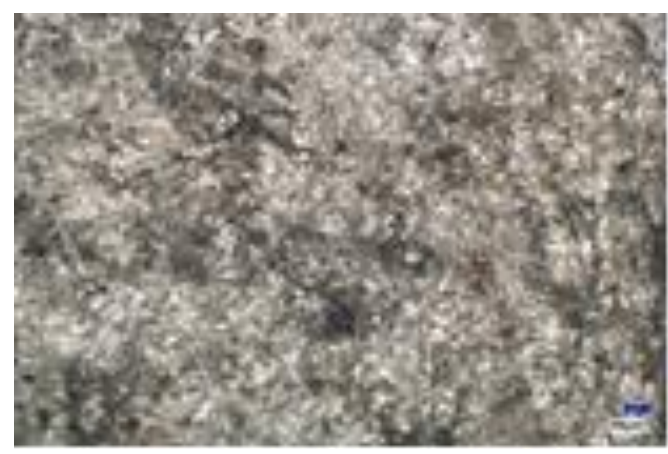

(a)

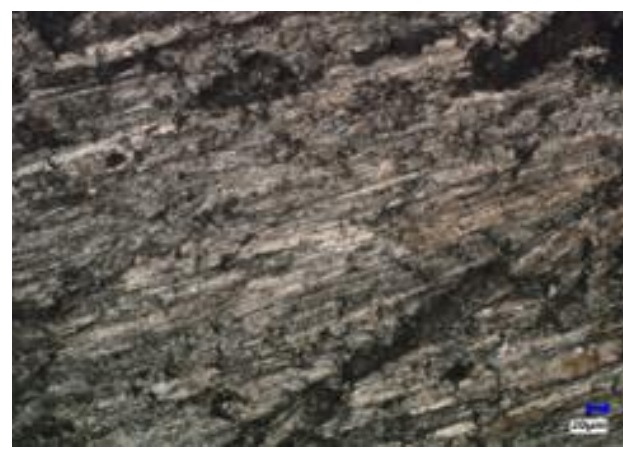

(b) 


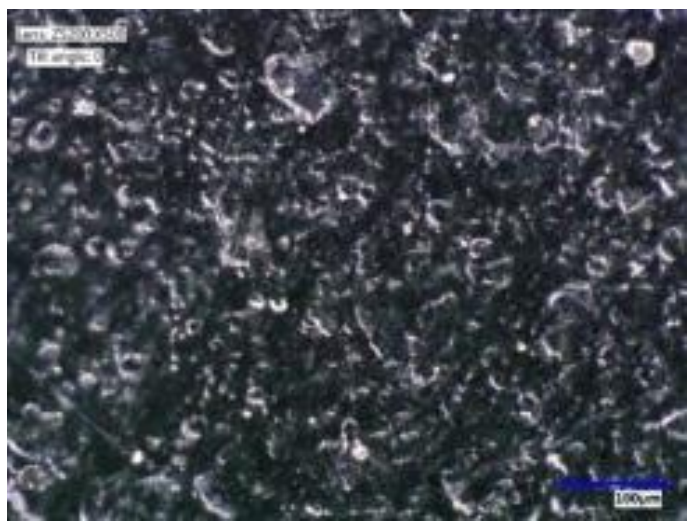

(c)

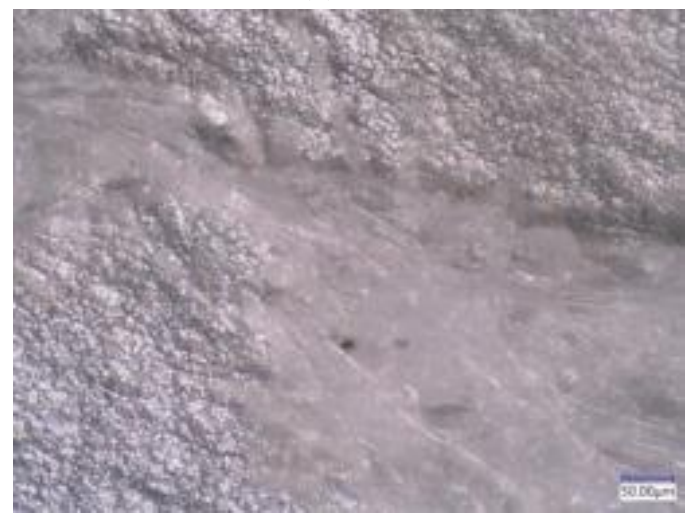

(e)

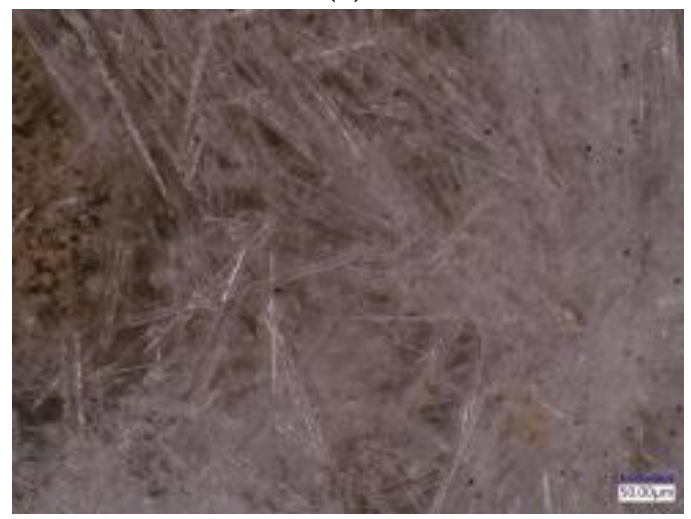

(g)

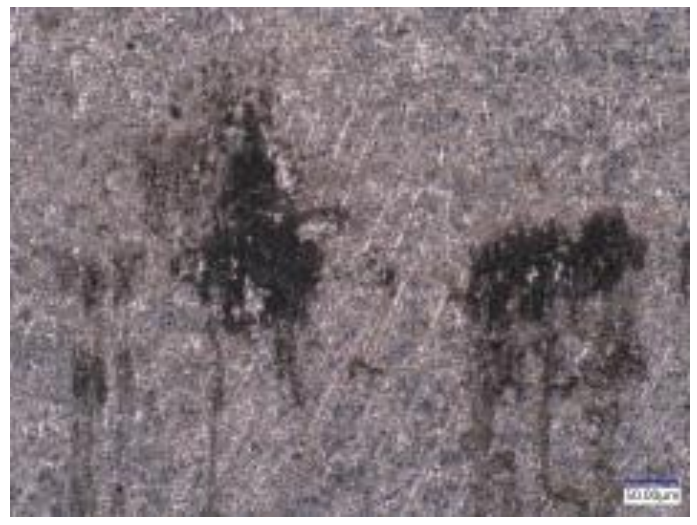

(i)

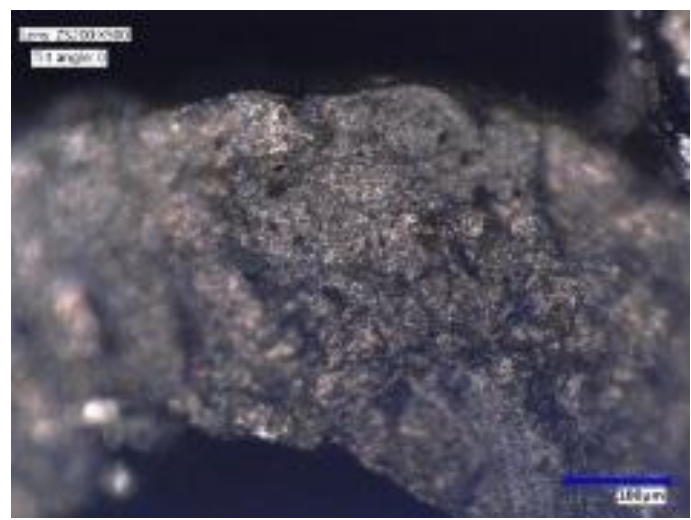

(d)

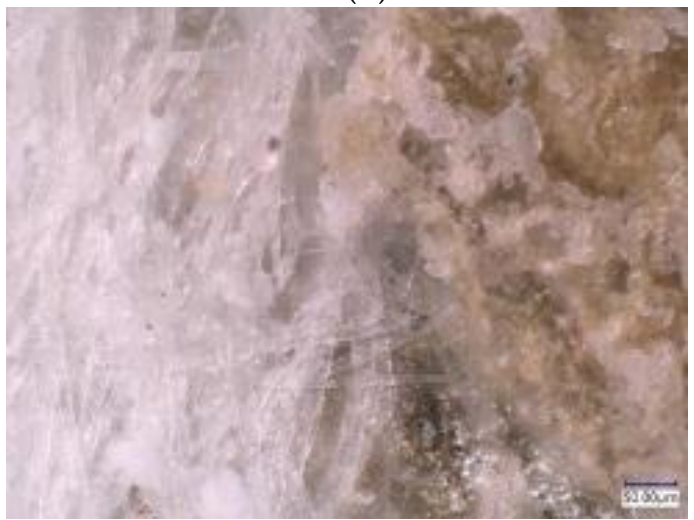

(f)

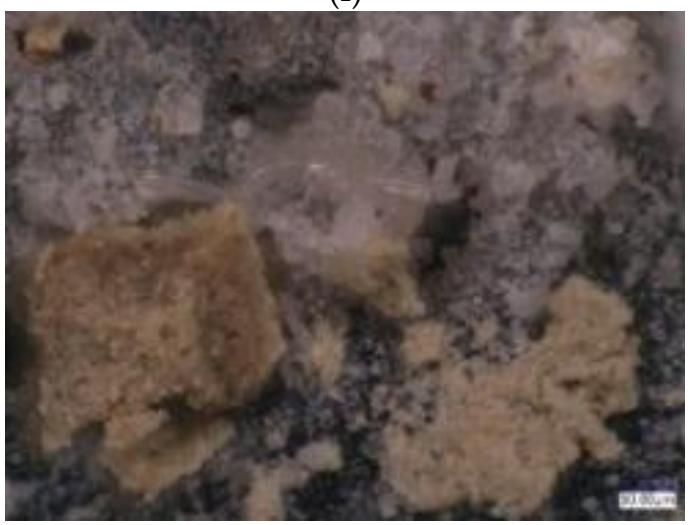

(h)

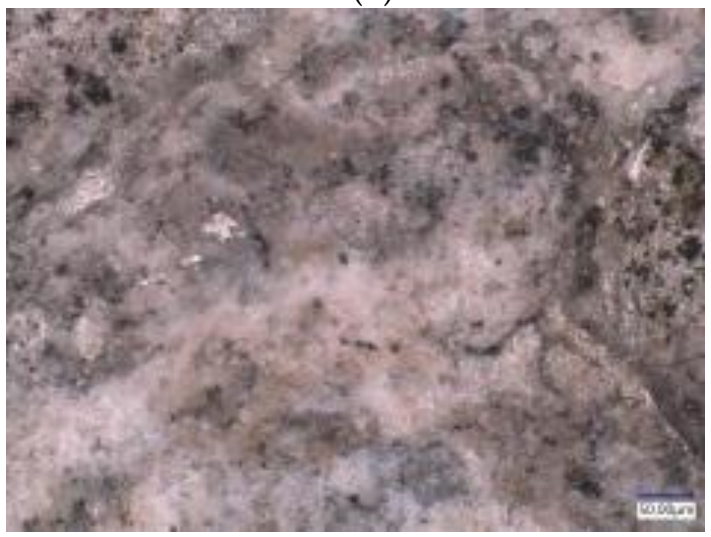

(j)

Gambar 2 hasil uji struktur mikro (a) sampel core impor sebelum dpanaskan (b) sampel core lokal sebelum dpanaskan (c) sampel core impor sesudah dipanaskan (d) sampel core lokal sesudah dipanaskan dipanaskan (e) sampel core impor direndam $\mathrm{H} 2 \mathrm{O} 4$ ( $f$ ) sampel core lokal direndam $\mathrm{H} 2 \mathrm{O} 4(\mathrm{~g})$ sampel core impor direndam $\mathrm{NAOH}(\mathrm{h})$ sampel core lokal direndam $\mathrm{NAOH}(i)$ sampel core impor direndam air radiator $(j)$ sampel core lokal direndam air radiator 
Pengujian komposisi kimia material radiator impor dan material radiator lokal dilakukan dengan menggunakan XRF sebelum direndam dengan larutan kimia dan sesudah direndam dengan larutan kimia.

Tabel 1 Perbandingan komposisi kimia sebelum uji korosi

\begin{tabular}{lccc}
\hline No & Unsur & Core Local & Core impor \\
\hline & & $\%$ & $\%$ \\
2 & $\mathrm{Al}$ & 0.31 & 0.90 \\
3 & $\mathrm{~S}$ & 0.045 & - \\
4 & $\mathrm{Cl}$ & 0.07 & - \\
5 & $\mathrm{~K}$ & 0.22 & - \\
6 & $\mathrm{Ca}$ & 26.3 & 39.2 \\
7 & $\mathrm{Ti}$ & 0.44 & 0.15 \\
8 & $\mathrm{~V}$ & 0.24 & 0.22 \\
9 & $\mathrm{Cr}$ & 0.11 & 0.1337 \\
10 & $\mathrm{Mn}$ & 2.16 & 27.5 \\
11 & $\mathrm{Fe}$ & 9.96 & 28.7 \\
12 & $\mathrm{NI}$ & 0.51 & 0.19 \\
13 & $\mathrm{Cu}$ & 13.9 & 0.75 \\
14 & $\mathrm{Zn}$ & 44.4 & 0.94 \\
15 & $\mathrm{Ga}$ & 1.20 & 1.06 \\
16 & $\mathrm{Zr}$ & 0.16 & 0.07 \\
\hline
\end{tabular}

Hasil pengujian komposisi kimia sebelum uji korosi pada material inti radiator dapat dilihat pada Tabel 1 kandungan material radiator lokal didominasi oleh Ca (26,3\%), Zn (44,4\%) dan Cu (13,9\%), dan pada material inti radiator impor, 3 unsur yang dominan adalah; $\mathrm{Cu}(2,48 \%)$, Fe $(45,15 \%)$, dan Mn $(44,88)$.

Tabel 2 perbandingan komposisi kimia setelah uji korosi

\begin{tabular}{|c|c|c|c|c|c|c|c|}
\hline & \multirow[t]{2}{*}{ Unsur } & \multicolumn{3}{|c|}{ lokal } & \multicolumn{3}{|c|}{ Mercedez } \\
\hline & & radiator & h2s04 & basa & radiator & h2s04 & basa \\
\hline 1 & $\mathrm{Al}$ & 14,15 & 30,31 & 5,47 & 41,08 & - & 6,72 \\
\hline 2 & $S$ & - & 31,35 & - & - & - & - \\
\hline 3 & $\mathrm{Cl}$ & - & - & - & - & - & - \\
\hline 4 & K & 11,31 & - & - & 2,13 & - & - \\
\hline 5 & $\mathrm{Ca}$ & 3,17 & - & 2,38 & - & 76,88 & 1,61 \\
\hline 6 & $\mathrm{Ti}$ & 0,45 & - & - & - & - & - \\
\hline 7 & V & - & - & - & - & - & - \\
\hline 8 & $\mathrm{Cr}$ & - & - & - & - & - & - \\
\hline 9 & $\mathrm{Mn}$ & 3,64 & 4,25 & 3,14 & 31,93 & & 38,39 \\
\hline 10 & $\mathrm{Fe}$ & 3,7 & 4,86 & 4,29 & 21,23 & & 31,65 \\
\hline 11 & NI & - & - & - & - & - & - \\
\hline 12 & $\mathrm{Cu}$ & 10,48 & 27,2 & 21,69 & - & 23,12 & 13,53 \\
\hline 13 & $\mathrm{Zn}$ & 48,38 & 0,74 & 63,03 & - & - & 6,7 \\
\hline 14 & $\mathrm{Ga}$ & - & 1 & - & 0,98 & - & - \\
\hline 15 & $\mathrm{Zr}$ & 0,489 & 0,29 & - & - & - & 1,15 \\
\hline 16 & $\mathrm{P}$ & 4,23 & - & - & 2,68 & - & - \\
\hline
\end{tabular}


Hasil pengujian komposisi kimia pada material inti radiator dapat dilihat pada Tabel 2 kandungan material radiator lokal yang direndam dengan cairan radiator didominasi oleh $\mathrm{Zn}(48,38), \mathrm{Al}(14,15)$ $\mathrm{K}(11,31), \mathrm{Cu}(10,48)$. Dan yang direndam dengan cairan $\mathrm{H} 2 \mathrm{SO} 4$ didominasi oleh $\mathrm{S}(31,35), \mathrm{Al}(30,31)$, $\mathrm{Cu}(27,20)$, sedangkan yang direndam dengan cairan Basa didominasi oleh $\mathrm{Zn}(63,03), \mathrm{Cu}(21,69)$.

Pada hasil pengujian komposisi kimia material inti radiator impor yang direndam dengan cairan radiator didominasi oleh $\mathrm{Al}(41,08), \mathrm{Mn}(31,93), \mathrm{Fe}(21,23)$, yang direndam dengan cairan $\mathrm{H} 2 \mathrm{SO} 4$ didominasi oleh $\mathrm{Ca}(76,88), \mathrm{Cu}(23,12)$ sedangkan yang direndam dengan cairan Basa ddominasi oleh $\mathrm{Mn}(38,39), \mathrm{Fe}(31,65)$, $\mathrm{Cu}(13,53)$.

Pengujian Kekerasan Pengujian kekerasan menggunakan metode micro-vickers, tujuan dari pengujian kekerasan ini adalah untuk mengetahui nilai kekerasan dari setiap sample material core radiator. Pengujian kekerasan dibagi menjadi dua bagian, (1) pengujian kekerasan sebelum proses perlakuan panas dan (2) pengujian kekerasan setelah perlakuan panas. Kedua pengujian ini dilakukan untuk membandingkan perubahan tingkat kekerasan material dari sebelum proses heat treatment dan setelah proses heat treatment.

Uji kekerasan micro-vickers menggunakan beban $100 \mathrm{gr} / \mathrm{f}$ dalam 10 detik.

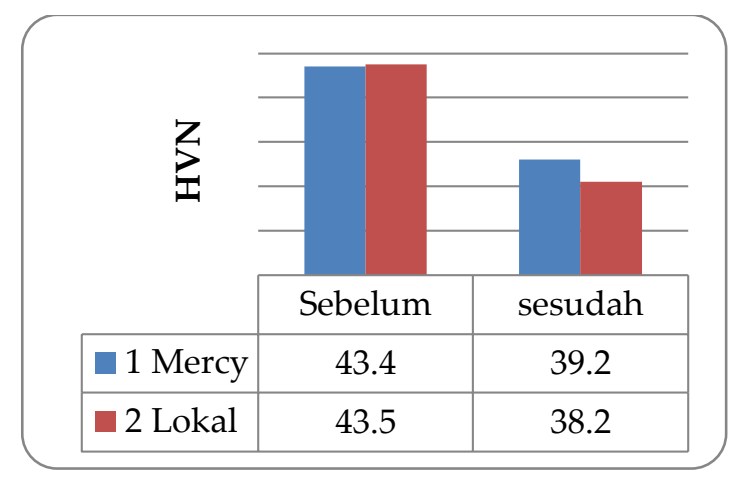

Gambar 3 Hasil uji kekerasan

Berikut hasil pengujian kekerasan pada dua tahap pengujian: Dari gambar di atas dapat dilihat nilai rata-rata kekerasan material radiator lokal sebelum dilakukan heat treatment adalah 43,5 HV dan setelah heat treatment sebesar 38,2 HV. Untuk material radiator impor, sebelum perlakuan panas adalah 43,4 HV dan setelah perlakuan panas 39,2 HV. Terjadi penurunan kekerasan pada sampel lokal setelah dilakukan pemanasan dengan suhu $850^{\circ} \mathrm{C}$ selama tiga jam. Hal ini disebabkan oleh proses self-deffuse atom.

Tabel 1 dan tabel 2 menunjukkan bahwa komposisi kimia bahan radiator Marcedes benz didominasi oleh $\mathrm{Ca}$, dan untuk komposisi kimia bahan radiator lokalnya adalah Zn. Masing-masing atom penyusun tersebut memiliki diameter atom yang berbeda-beda, sehingga akan mempengaruhi mekanisme selfdiffuse yang mempengaruhi nilai kekerasan.

\section{KESIMPULAN}

Pengamatan struktur mikro terhadap kedua jenis material sebelum dipanaskan, menunjukkan bahwa material inti radiator Mercedez benz sebelum proses heat treatment menggunakan mikroskop optik menunjukkan bahwa matriks atom dan batas butirnya belum terlihat, hanya terlihat sekelompok butiran putih dan sekelompok butiran hitam pada material radiator setempat. Tidak ada kumpulan atom dan batas matriks dan butir. Pada material radiator lokal terlihat garis-garis hitam memanjang dan sekelompok besar butiran-butiran putih dari material radiator Mercedez lebih banyak dibandingkan material radiator lokal. Garis yang memanjang secara substansial pada material radiator lokal lebih banyak dan lebih besar daripada material Radiator Mercedez. Butir putih pada material radiator Mercedez lebih banyak dibandingkan material radiator lokal. Hasil pengamatan struktur mikro setelah sampel dipanaskan $850^{\circ} \mathrm{C}$ selama 3 jam pada material inti radiator, didapat hasil yang terlihat melingkari warna yang sangat hitam, seperti cincin melingkar. Ada beberapa corak putih. Sementara itu, material radiator lokal setelah dipanaskan terlihat seperti potongan roda yang besar dan warnanya tidak terlalu 
hitam. Hasil pengamatan struktur mikro setelah kedua sampel direndam dengan cairan $\mathrm{H} 2 \mathrm{SO} 4, \mathrm{NAOH}$, dan cairan radiator terlihat perubahan warna. Hal tersebut dipengaruhi oleh perubahan unsur yang dominan dan tidak dominan akibat pengujian korosi tersebut.

Uji komposisi kimia menunjukkan bahwa kandungan material radiator lokal didominasi oleh Ca (26,3\%), Zn (44,4\%) dan Cu (13,9\%). Material inti radiator Mercedez memiliki tiga kandungan elemen dominan yaitu; $\mathrm{Cu}(2,48 \%)$, Fe (45,15\%), dan Mn (44,88\%). Sementara itu, hasil uji komposisi kimia material inti radiator lokal yang direndam dengan cairan radiator didominasi oleh $\mathrm{Zn}(48,38), \mathrm{Al}(14,15)$ $\mathrm{K}(11,31), \mathrm{Cu}(10,48)$, dan yang direndam dengan cairan $\mathrm{H} 2 \mathrm{SO} 4$ didominasi oleh $\mathrm{S}(31,35), \mathrm{Al}(30,31)$, $\mathrm{Cu}(27,20)$, sedangkan yang direndam dengan cairan Basa didominasi oleh $\mathrm{Zn}(63,03), \mathrm{Cu}(21,69)$. Pada hasil pengujian komposisi kimia material inti radiator Mercedez yang direndam dengan cairan radiator didominasi oleh $\mathrm{Al}(41,08), \mathrm{Mn}(31,93), \mathrm{Fe}(21,23)$, yang direndam dengan cairan $\mathrm{H} 2 \mathrm{SO} 4$ didominasi oleh $\mathrm{Ca}(76,88), \mathrm{Cu}(23,12)$, sedangkan yang direndam dengan cairan Basa ddominasi oleh $\mathrm{Mn}(38,39), \mathrm{Fe}(31,65)$, $\mathrm{Cu}(13,53)$. Kekerasan material inti radiator Mercedez sebelum pemanasan $43,4 \mathrm{HV}$, setelah dipanaskan 39,2 HV. Kekerasan material radiator lokal sebelum pemanasan 43,5 dan setelah pemanasan 38,2 HV.

\section{REFERENCES}

[1] Elsaid M. Experimental Study On The Heat Transfer Performance and Friction Factor Characteristic of $\mathrm{CO} 3 \mathrm{O} 4$ and $\mathrm{Al} 2 \mathrm{O} 3$ Based $\mathrm{H} 2 \mathrm{O} /(\mathrm{CH} 2 \mathrm{OH}) 2$ Nanofluids in Vehicle Engine Radiator. Journal of International Communications in Heat and Mass Transfer. 2019;108.

[2] Pan' cikiewicz K, Radomski W. Lack of Tightness Analysis of Concealed Welded Radiators. Journal of Engineering Failure Analysis. 2020;114.

[3] Ramesh J, Ladumor VYG, Araniya KK. A review Paper on Analysis of Automobile Radiator. International Journal of Research and Scientific Innovation. 2014;1(8).

[4] of Trade M. Perkembangan Impor Menurut HS 6 Digit; 2020. Available from: https://statistik.kemendag.go.id/import-growth-hs-6-digits.

[5] Prakash RPL, Selvam M, Pandian AAS, Palani S, Harish KA. Design and Modification of Radiator in I. C. Engine Cooling System for Maximizing Efficiency and Life. Indian Journal of Science and Technology. 2016;92:2-9.

[6] Dubey AK. Investigation on Suitability of Alumnium to Copper in a Radiator. Journal of Manufacturing Science and Technology. 2015;3(1):16-23.

[7] Dwiwandono R, Firmansyah L, Herbirowo S, Hasbi MY, Citrawati F. Analisa Strukturmikro dan Pengaruhnya Terhadap Sifat Mekanis Batangan Rel Tipe R54. Jurnal Metalurgi. 2017;2(67-76).

[8] Muthuchamy A, Annamalai R, Acharyya SG, Nagaraju N, Agrawai DK. Microstructureal and Electrocemical Behaviour of Alumuniu Alloy Composites Produced Using Different Sintering Technuques. Journal of Material Research. 2018;21(3):2-7.

[9] Jha SK, Balakumar D, Paluchamy R. Experimental Analysis Microstructure and Mechanical Properties of Copper and Brass Based Alloys. International Journal of Automotive and Mechanical Engineering. 2015;11:2317-2331.

[10] Fadare DA, Fadara TG, Akanbi OY. Effect of Heat Treatment on Mechanical Properties and Microstructure of NST 37-2 Steel. Journal of Materials Characterization \& Engineering. 2011;10(3).

[11] Ismail NM, Khatif NAA, Kecik MAKA, Shaharudin MAH. The effect of heat treatment on the hardness and impact properties of medium carbon steel. IOP Conf Series: Materials Science and Engineering. 2016;11:2-9.

[12] Li K, Zhang J, Chen X, Yin Y, He Y, Zhou Z, et al. Microstructure Evolution of Eutectic Si in Al-7Si Binary Alloy by Heat Treatment and Its Effect in Enhanching Thermal Conductivity. Journal of Material Research and Technology. 2020;9(4):8780-8786. 